OPEN ACCESS

Edited by:

Lars Matthias Voll,

Friedrich-Alexander University

Erlangen-Nürnberg, Germany

Reviewed by:

Axel Tiessen,

Centro de Investigación y de Estudios

Avanzados del IPN, Mexico

Zhenzhu Xu,

Institute of Botany, China

*Correspondence:

Jianguang Hu

jghu2003@263.net

${ }^{\dagger}$ These authors have contributed equally to this work.

Specialty section:

This article was submitted to

Plant Physiology,

a section of the journal

Frontiers in Plant Science

Received: 27 March 2016

Accepted: 09 June 2016

Published: 22 June 2016

Citation:

Li W, Liu J, Ashraf U, Li G, Li Y

Lu W, Gao L, Han F and Hu J (2016) Exogenous $\gamma$-aminobutyric Acid (GABA) Application Improved Early Growth, Net Photosynthesis, and Associated Physio-Biochemical

Events in Maize.

Front. Plant Sci. 7:919.

doi: 10.3389/fpls.2016.00919

\section{Exogenous $\gamma$-aminobutyric Acid (GABA) Application Improved Early Growth, Net Photosynthesis, and Associated Physio-Biochemical Events in Maize}

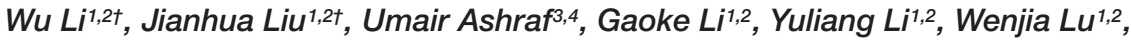 \\ Lei Gao ${ }^{1,2}$, Fuguang $\mathrm{Han}^{1,2}$ and Jianguang $\mathrm{Hu}^{1,2 *}$ \\ ${ }^{1}$ Crop Research Institute, Guangdong Academy of Agricultural Sciences, Guangzhou, China, ${ }^{2}$ Key Laboratory of Crops \\ Genetics and Improvement of Guangdong Province, Guangzhou, China, ${ }^{3}$ Department of Crop Science and Technology, \\ College of Agriculture, South China Agricultural University, Guangzhou, China, ${ }^{4}$ Scientific Observing and Experimental \\ Station of Crop Cultivation in South China, Ministry of Agriculture, Guangzhou, China
}

$\gamma$-aminobutyric acid (GABA) is an endogenous signaling molecule and involved in growth regulations and plant development, however, a little information is available on the consequences of exogenous GABA application on growth, development, and associated physio-biochemical processes in maize. The present study examined the GABA-induced regulations in early growth, net photosynthetic rate, gas exchange, osmoregulation, and enzymatic activities in three maize cultivars, i.e., Yuecainuo 6, Zhengtian 68, and Yuecainuo 2. Two levels of GABA, i.e., $0 \mathrm{mg} \mathrm{L}^{-1}$ and $50 \mathrm{mg} \mathrm{L}^{-1}$, in solution form, with total application volume of $100 \mathrm{ml}$ per pot containing 15 maize seedlings were exogenously applied. Results revealed that exogenous GABA application improved seedling growth in terms of seedling length and biomass accumulation in all maize cultivars at both 3 and 7 days after treatment (DAT). It also promoted net photosynthesis and variably affected gas exchange attributes, i.e., stomatal conductance (Gs), intercellular $\mathrm{CO}_{2}$ concentration (Ci), and transpiration rate $(\mathrm{Tr})$, as well as leaves SPAD value. Furthermore, lipid peroxidation [in terms of malondialdehyde (MDA)] under GABA treated maize seedlings were also remained variable; however, osmolyte accumulation (protein and proline) and activities of anti-oxidants enzymes, i.e., super-oxide dismutase and peroxidase were also affected differently at both 3 and 7 DAT in all maize cultivars. Furthermore, enzymes involved in nitrogen metabolism, e.g., nitrate reductase and glutamine synthetase were improved. These results suggest the involvement of GABA in various physio-metablical mechanisms which might lead to improvement in morphological growth of maize. In future, research is still needed at molecular and genetic levels to unravel the involvement of GABA-mediated regulations in growth and its associated physio-biochemical mechanisms.

Keywords: anti-oxidant enzymes, growth, maize, photosynthesis, osmoregulation 


\section{INTRODUCTION}

Plants have complex mechanisms of inter and intra cellular signal transductions which play a major role in growth regulation and plant development. This system of plant signaling not only controls the growth behavior but also projects the complete life cycle or whole growth period of a plant. Plant signaling molecules are important in this regard in which they integrate external stimuli to internal plant processes for an appropriate response. Most often, plants respond to these signaling molecules at the level of their biosynthesis, transportation, and uptake or at the level when these are perceived (Ma, 2003; Bouche and Fromm, 2004; Roberts, 2007).

$\gamma$-Aminobutyric acid (GABA), four-carbon non-protein amino acid, is well recognized as an endogenous plant signaling molecule and involved in various physio-biochemical processes of a plant. For example, it triggers up the nitrate uptake and nitrate transport gene expression (BnNrt 2) the in Brassica napus and regulates 14-3-3 gene family members in seedling of Arabidopsis thaliana (Beuve et al., 2004; Lancien and Roberts, 2006). Development of pollen tube and its orientation is also related to GABA levels in the tobacco plants (Yu and Sun, 2007). GABA-induced alleviation of proton and aluminum stress is well explored by Song et al. (2010) at seedling stage in barley whereas regulation of gene expression associated with $\mathrm{H}_{2} \mathrm{O}_{2}$ and ethylene production in the roots of Caragana intermedia is also related with endogenous GABA application (Shi et al., 2010). Activation of antioxidant defense system to scavenge ROS and to palliate oxidative damage is also a boon of GABA in peach under chilling stress (Yang et al., 2011). Additionally, endogenous GABA levels in plants are very low; however, it was produced rapidly in plants under stressful conditions to withstand against them (Kinnersley and Turano, 2000). Exogenous application of GABA promoted morphological growth, functioning of photosynthetic machinery, gas exchange capacities, chlorophyll biosynthesis, enzymatic, and non-antioxidant responses and membrane stabilization in tomato (Luo et al., 2011). Furthermore, roles of GABA in osmoregulation, $\mathrm{pH}$ change, glutamate homeostasis and its action as a signaling source for nitrate uptake are important with respect to plant response to external environments (Carroll et al., 1994; Shelp et al., 1999; Masclaux-Daubresse et al., 2002; Beuve et al., 2004) whilst GABA is also involved in nitrogen metabolism (storage or transport) and C:N fluxes.

$\gamma$-aminobutyric acid is synthesized in a complicate pathway called the GABA shunt (conversion of glumate to succinate) which includes three main enzymes, i.e., glutamate decarboxylase (GAD), GABA transaminase, and succinic semialdehyde dehydrogenase (SSADH), of which GAD is the key enzyme which is responsible for irreversible $\alpha$-decarboxylation of glutamate "the first step of the GABA shunt". Secondly, GABA is catalyzed to succinate semialdehyde reversibly by the action of GABA transaminase where $\alpha$-ketoglutaric acid or pyruvate acts as amino acceptors. Finally, succinic semialdehyde is irreversibly oxidized to succinate (Rhodes et al., 1999). Moreover, GABA might also be produced from $\gamma$-aminobutyraldehyde (a product of the polyamine catabolic pathway) through betaine aldehyde dehydrogenase which localized in chloroplasts and also involved in biosynthesis of glycinebetaine. Exogenous application of different plant growth regulators, phyto-hormones and growth promoters have proved their significant impacts in growth regulations in maize (Anjum et al., 2011a,b,c); however, reports on the effects of GABA application on early maize growth and its involvement in various metabolic events are very few. This study examined the GABA-induced regulations in early performance of maize seedling, photosynthetic and gas exchange capacities, and anti-oxidative defense system to protect against oxidative stress with the hypothesis that GABA may improve early performance of maize by regulating its related physio-biochemical processes.

\section{MATERIALS AND METHODS}

\section{Experimental Material and Growing Conditions}

A pot experiment was conducted by using three popular maize varieties, i.e., Yuecainuo 6, Zhengtian 68, and Yuecainuo 2 collected from Crop Research Institute, Guangdong Academy of Agricultural Sciences, Guangzhou, China. This region has a humid subtropical monsoonal type of climate characterized by hot summers and warm winters with yearly average temperature ranged from 21 to $29^{\circ} \mathrm{C}$ (Li et al., 2016; Mo et al., 2016) The cultivars used in this study are well-recognized and widely grown corn cultivars in South China. Before sowing, healthy seeds with uniform color, shape and with intact seed coat were selected from the seed lot and sown in plastic pots $(18 \mathrm{~cm} \times 13 \mathrm{~cm} \times 6 \mathrm{~cm})$ containing sandy loam soil with total nitrogen $0.97 \mathrm{~g} \mathrm{~kg}^{-1}$, total phosphorous $0.82 \mathrm{~g} \mathrm{~kg}^{-1}$, total potassium $25.50 \mathrm{~g} \mathrm{~kg}^{-1}$, and $\mathrm{pH} 6$. The pots were placed at room conditions $\left(28^{\circ} \mathrm{C}\right)$ under sun light with light/dark period of $12 / 12 \mathrm{~h}$ and $60 \pm 5 \%$ relative humidity (RH).

\section{Treatments}

Two levels of GABA (Sigma) $\left(0 \mathrm{mgL}^{-1}\right.$ (-GABA) and $50 \mathrm{mgL}^{-1}$ (+GABA), in solution form), with total application volume of $100 \mathrm{ml}$ per pot and split into twice $(50 \mathrm{ml}$ for 15 days after sowing (DAS), the rest $50 \mathrm{ml}$ were applied at 16 DAS), were exogenously applied to the seedlings (at 2-3 leaves stage). The $\mathrm{pH}$ of the solution was 7.0 (the same as the control (distilled water application). For each variety, 25 seeds per pot were sown with 10 pots per treatment whilst at first fully expanded leaves, 15 seedlings with consistent growth were kept in each pot and other pants were thinned out. The treatments were arranged in completely randomized design (CRD).

\section{Observations}

\section{Photosynthesis and SPAD Value}

The photosynthesis characters were measured with the portable photosynthesis system (LI-6400, LI-COR, USA) during 9:0011:00 am according to Pan et al. (2015). The top fully expanded leaves of two represented seedlings from each three different pots of each cultivar were selected to measure the net photosynthetic rate $(\mathrm{Pn})$, stomatal conductance $(\mathrm{Gs})$, intercellular $\mathrm{CO}_{2}$ concentration $(\mathrm{Ci})$, and transpiration rate 
(Tr) with the following adjustments: photo-synthetically active radiation at leaf surface was up to $1200 \mu \mathrm{mol} \mathrm{m} \mathrm{m}^{-2} \mathrm{~s}^{-1}$, molar flow of air per unit leaf area was $500 \mu \mathrm{mol} \mathrm{s}{ }^{-1}$, ambient $\mathrm{CO}_{2}$ concentration was $400 \mu \mathrm{mol} \mathrm{mol}{ }^{-1}$, air temperature was $30^{\circ} \mathrm{C}$, and $\mathrm{RH}$ was $60 \%$. The SPAD values represented as chlorophyll contents were recorded with a SPAD meter 'SPAD502' (Konica Minolta, Japan) according to Wu et al. (1998) that provided a precise, rapid and non-destructive estimation of leaf chlorophyll contents. The average SPAD values (determination was done at the upper $1 / 3 \mathrm{rd}$, middle, and lower $1 / 3 \mathrm{rd}$ SPAD value in leaves) was considered as the relative chlorophyll content.

\section{Physiological Parameters}

To determine physiological parameters, a total number of 25 seedlings were harvested from 5 pots ( 5 seedlings per pot), separated into leaves and roots and immediately dropped into liquid nitrogen for $30 \mathrm{~s}$ then stored at $-80^{\circ} \mathrm{C}$ till biochemical analyses.

The soluble protein content was measured base on the method of Bradford (1976) by using G-250. Briefly, $0.1 \mathrm{~g}$ of tissue was homogenized with $1 \mathrm{ml}$ of $0.1 \mathrm{M}$ ice-cold phosphate buffer, $\mathrm{pH} 7.0$, containing $1 \%$ polyvinylpolypyrrolidone. The resulting homogenate was centrifuged at $10,000 \mathrm{~g}$ at $4^{\circ} \mathrm{C}$ for $10 \mathrm{~min}$, and the supernatant was immediately used for soluble protein measurements. The supernatant was mixed with the comassie brilliant blue-G250 solution and the absorbance of the reaction mixture was read at $595 \mathrm{~nm}$ with a spectrophotometer. Protein content was determined from a standard curve (bovine serum albumin) and expressed as $\mu \mathrm{g} \mathrm{g}^{-1}$.

The proline content was measured by method of Bates et al. (1973) by using ninhydrin. The fresh sample of $0.3 \mathrm{~g}$ was homogenized in 3\%sulphosalycylic acid and homogenate filtered through filter paper. After addition of acid ninhydrin and glacial acetic acid, the mixture was then heated in water bath at $100^{\circ} \mathrm{C}$ for $1 \mathrm{~h}$. Reaction was then stopped by using ice bath. After reaction the absorbance of the red chromosphere in the toluene fraction was measured at $520 \mathrm{~nm}$. Proline content was determined using calibration curve and expressed as $\mu \mathrm{mol} \mathrm{g}^{-1}$.

The malondialdehyde (MDA) content was measured by the method of Chen and Wang (2006). Fresh sample (0.3 g) was homogenized in $5 \mathrm{ml}$ of $10 \%$ trichloroacetic acid and centrifuged at $4000 \mathrm{~g}$ for $15 \mathrm{~min}$. To each $2 \mathrm{ml}$ of the supernatant, $2 \mathrm{~mL}$ of $0.6 \%$ thiobarbituric acid in 10\% TCA was added. The mixtures were heated at $100^{\circ} \mathrm{C}$ for $15 \mathrm{~min}$ and then quickly cooled in an ice bath. After centrifugation at $10,000 \mathrm{~g}$ for $20 \mathrm{~min}$, the absorbance of the reaction solutions was recorded at $532 \mathrm{~nm}$, $600 \mathrm{~nm}$, and $450 \mathrm{~nm}$. The MDA content of the reaction solutions was calculated as: MDA content $\left(\mu \mathrm{molL}^{-1}\right)=6.45$ (OD532OD600)-0.56OD450, and final result of MDA was expressed as $\mu \mathrm{molg}^{-1}$.

The super-oxide dismutase (SOD, EC 1.15.1.1) activity was measured by using nitro blue tetrazolium (NBT) method (Chen and Wang, 2006). After reaction, the color changed was measured at $560 \mathrm{~nm}$, and one unit of SOD activity equaled the volume of extract needed to cause $50 \%$ inhibition of the color reaction and express as $\mathrm{U} \mathrm{g}^{-1}$.
For peroxidase (POD, EC1.11.1.7) activity, enzyme extract $(50 \mu \mathrm{l})$ was added to the reaction solution system containing $1 \mathrm{ml} 0.3 \% \mathrm{H}_{2} \mathrm{O}_{2}, 0.95 \mathrm{ml} 0.2 \%$ guaiacol, and $1 \mathrm{ml} 50 \mathrm{mmol} / \mathrm{L}$ $\mathrm{pH}$ 7.0PBS, the absorbance change of the brown guaiacol at $470 \mathrm{~nm}$ was recorded for calculating POD activity. One POD unit of enzyme activity was defined as the absorbance increase because of guaiacol oxidation by $0.01\left(\mathrm{Ug}^{-1}\right)$ (Chen and Wang, 2006).

The glutamine synthetase (GS, EC 6.3.1.2) activity was measured according Sun et al. (2009). The reaction system containing $50 \mathrm{mM}$ imidazole, $18 \mathrm{mM}$ ATP-Na $2,28 \mathrm{mM} \mathrm{MgCl}_{2}$, $25 \mathrm{mM}$ hydroxylamine, $92 \mathrm{mM}$ l-glutamate-Na, ( $\mathrm{pH}$ 7.2). The enzyme reaction was terminated with $500 \mu \mathrm{l}$ of stopping solution containing $370 \mathrm{mM} \mathrm{FeCl} 3,200 \mathrm{mM}$ TCA, $700 \mathrm{mM} \mathrm{HCl}$. After centrifugation $(5 \mathrm{~min}, 13,000 \mathrm{~g}$ ) $600 \mu \mathrm{l}$ of supernatant was mixed with $300 \mu \mathrm{l}$ of water, and read at $540 \mathrm{~nm}$ and expressed as $\Delta \mathrm{A}$. $\mathrm{mg}^{-1}$ protein $\mathrm{h}^{-1}$ and $\Delta \mathrm{A}$ represents the change of absorption value.

The nitrate reductase (NR, EC 1.7.99.4) activity was determined by the method of Sun et al. (2009). The extract was incubated in a reaction mixture containing $100 \mathrm{mM}$ potassium phosphate buffer ( $\mathrm{pH}$ 7.4), $10 \mathrm{mM}$ EDTA, $0.15 \mathrm{mM} \mathrm{NADH}$, and $0.1 \mathrm{M} \mathrm{KNO}_{3}$ at $30^{\circ} \mathrm{C}$ for $30 \mathrm{~min}$. The reaction was stopped by the addition of TCA. The absorbance of the supernatant was determined at $540 \mathrm{~nm}$ after adding sulfanilamide and $N$-(1-napthyl)ethylenediamine-dihydrochloride. The units was expressed as $\mu \mathrm{g}$ $\mathrm{g}^{-1} \mathrm{FW} \mathrm{h}^{-1}$.

\section{Morphological Characters}

The rest of the seedlings, total 50 seedlings in each treatment (10 seedlings per pot and 5 pots per treatment) were harvested for the measurements of the root and shoot fresh and dry weight, seedling length, weight per unit height, and root shoot ratio. The root and shoot fresh weight of the plant from each pot was weighted by the electronic analytical balance (BSA224S, Sartorius, Taiwan) immediately after harvesting. After weighing of the fresh weight, the shoot part of the plant was used for measuring of the seedling length by a plastic ruler. Then the fresh sample of the root and shoot part of the plant was placed in the oven, dried at $80^{\circ} \mathrm{C}$ to constant weight for measurement of the root and shoot dry weight. The plant weight per unit seedling length and root/shoot ratio was determined with the following formulae:

Plant weight per unit seedling length $\left(\mathrm{mg} \mathrm{cm}^{-1}\right)=$ dry weight of the shoot/seedling length.

Root shoot weight ratio = dry weight of the root /dry weight of the shoot.

\section{Statistical Analysis}

Analyses of variances (ANOVA) were performed by the Linear Model Procedure of Statistix version 8 (Statistix 8, Analystical, Tallahassee, FL, USA). Comparisons of means among different treatments were made according to the least significant difference (LSD) at the $5 \%$ probability level. The figures were made by using the SigmaPlot for windows version 10. 0 (Systat Software Inc., San Jose, CA, USA). 


\section{RESULTS}

\section{Analysis of Variance of the Investigated Parameters}

All maize verities differed significantly regarding most of the investigated parameters in both sampling stags, except for $\mathrm{Ci}$ and NR activity in leaves at 3 DAT and for SOD activity and MDA content in root and GS and NR activity in leaves at 7 DAT. GABA application also affected some of the investigated parameters; nevertheless, no significant effect was noted for shoot weight per unit height, root shoot weight ratio, $\mathrm{Ci}$, proline and MDA contents in leaves of both harvest stages. Moreover, activities of POD, GS, and NR in leaves at 3 DAT and root dry weight and GS activity in leaves at 7 DAT were also affected considerably. For variety and GABA interaction, the significant effects were observed for root and shoot fresh weight, $\mathrm{Ci}$, SPAD values in leaves, protein content in both leaves and roots, SOD activity in leaves, and MDA content in roots at both 3 and 7 DAT (Table 1).

\section{Morphological Characters}

$\gamma$-aminobutyric acid treated maize seedlings improved root fresh weight of Yuebainuo 6, Zhengtian 68, and Yuecainuo 2 at 3 DAT by $45.30,23.57$, and $49.45 \%$, respectively, compared with non-treated seedlings (Figure 1A). At 7 DAT, GABA treated seedlings showed significant increase in root fresh weight by
$26.82 \%$ for Yuebainuo 6 and by $38.88 \%$ for Zhengtian 68, but no significant difference was observed for Yuecainuo 2 (Figure 1B). With GABA application, the shoot fresh weight was improved up to 27.33, 3.52, and 33.09\% for Yuebainuo 6, Zhengtian 68, and Yuecainuo 2, respectively, at $3 \mathrm{DAT}$, and the significance was detected for Yuebainuo 6 and Zhengtian 68 only whereas a remarkable increase in shoot fresh weight was observed for Yuebainuo 6, Zhengtian 68, and Yuecainuo 2 by 38.11, 42.33, and $12.71 \%$, respectively, at 7 DAT (Figures 1C,D).

$\gamma$-aminobutyric acid treated seedlings improved root dry weight by $34.80 \%$ for Yuecainuo 2 at 3 DAT and by $16.60 \%$ for Yuebainuo 6 at 7 DAT (Figures 2A,B) whilst a notable increase in shoot was observed for Yuecainuo $2(23.47 \%)$ at 3 DAT. Furthermore, a significant improvement in shoot dry weight was recorded for Yuebainuo 6, Zhengtian 68, and Yuecainuo 2 at 7 DAT by 22.10, 21.73, and 13.16\%, respectively, (Figures 2C,D).

Additionally, under GABA treatment, the seedling length was significantly improved for Yuebainuo 6 and Yuecainuo 2 at $3 \mathrm{DAT}$, and for Zhengtian 68 at 7 DAT, nevertheless, nonsignificant effect of GABA application was observed for the shoot weight per unit seedling length and root shoot weight ratio (Figure 3).

\section{Photosynthesis and Gas Exchange}

$\gamma$-aminobutyric acid-induced enhancement in net photosynthetic rate $(\mathrm{Pn})$ were recorded for Yuebainuo 6 and

TABLE 1 | Analysis of variance of the investigated parameters.

\begin{tabular}{|c|c|c|c|c|c|c|}
\hline \multirow[t]{2}{*}{ Index } & \multicolumn{3}{|c|}{3 DAT } & \multicolumn{3}{|c|}{7 DAT } \\
\hline & $\mathbf{v}$ & $\mathbf{T}$ & $\mathbf{V} \times \mathbf{T}$ & $\mathbf{v}$ & $\mathbf{T}$ & $\mathbf{V} \times \mathbf{T}$ \\
\hline Root fresh weight & $16.56^{* *}$ & $76.52^{* *}$ & $6.41^{*}$ & $47.10^{* *}$ & $17.47^{* *}$ & $4.51 *$ \\
\hline Shoot fresh weight & $34.16^{* *}$ & $34.25^{* *}$ & $6.77^{*}$ & $14.87^{* *}$ & $44.48^{* *}$ & $4.40^{*}$ \\
\hline Root dry weight & $37.49^{* *}$ & $6.43^{*}$ & $2.71 \mathrm{~ns}$ & $70.72^{* *}$ & $2.25 \mathrm{~ns}$ & $1.48 \mathrm{~ns}$ \\
\hline Shoot dry weight & $25.47^{* *}$ & $8.62^{*}$ & $2.44 \mathrm{~ns}$ & $25.38^{* *}$ & $43.28^{* *}$ & $1.41 \mathrm{~ns}$ \\
\hline Plant height & $113.95^{* *}$ & $104.19^{* *}$ & $28.10^{* *}$ & $28.40^{* *}$ & $41.68^{* *}$ & $3.91 \mathrm{~ns}$ \\
\hline Shoot weight per unit height & $18.70^{* *}$ & $0.01 \mathrm{~ns}$ & $0.78 \mathrm{~ns}$ & $41.20^{* *}$ & $0.40 \mathrm{~ns}$ & $2.19 \mathrm{~ns}$ \\
\hline Root shoot weight ratio & $6.93^{*}$ & $0.25 n s$ & $0.22 \mathrm{~ns}$ & $85.04^{* *}$ & $3.51 \mathrm{~ns}$ & $0.16 n s$ \\
\hline Pn in leaves & $21.26^{* *}$ & $77.40^{* *}$ & $27.72^{* *}$ & $164.31^{* *}$ & $55.52^{* *}$ & $0.02 \mathrm{~ns}$ \\
\hline Gs in leaves & $36.63^{* *}$ & $11.37^{* *}$ & $0.24 \mathrm{~ns}$ & $117.92^{* *}$ & $5.67^{*}$ & $2.56 n s$ \\
\hline Ci in leaves & $4.22 \mathrm{~ns}$ & $2.91 \mathrm{~ns}$ & $11.07^{* *}$ & $420.51 * *$ & $0.15 \mathrm{~ns}$ & $4.47^{*}$ \\
\hline Tr in leaves & $91.51^{* *}$ & $11.02^{* *}$ & $0.81 \mathrm{~ns}$ & $121.35^{* *}$ & $24.08^{* *}$ & $11.25^{* *}$ \\
\hline SPAD value in leaves & $395.46^{* *}$ & $1.45 \mathrm{~ns}$ & $19.23^{* *}$ & $321.23^{* *}$ & $53.95^{* *}$ & $30.97^{* *}$ \\
\hline Protein content in leaves & $233.57^{* *}$ & $50.01^{* *}$ & $43.22^{* *}$ & $117.87^{* *}$ & $105.90^{* *}$ & $80.67^{* *}$ \\
\hline Protein content in roots & $7872.24^{* *}$ & $22971.2^{* *}$ & $7814.13^{* *}$ & $517.23^{* *}$ & $2437.08^{* *}$ & $628.13^{* *}$ \\
\hline Proline content in leaves & $177.42^{* *}$ & $0.36 n s$ & $0.69 n s$ & $18.89 * *$ & $2.51 \mathrm{~ns}$ & $5.33^{*}$ \\
\hline SOD activity in leaves & $156.99 * *$ & $5.43^{*}$ & $4.33^{*}$ & $77.99^{* *}$ & $40.17^{* *}$ & $42.42^{* *}$ \\
\hline SOD activity in roots & $59.71^{* *}$ & $35.88^{* *}$ & $23.41^{* *}$ & $1.47 \mathrm{~ns}$ & $8.96 *$ & $0.97 \mathrm{~ns}$ \\
\hline POD activity in leaves & $15.48^{* *}$ & $1.37 \mathrm{~ns}$ & $4.24 \mathrm{~ns}$ & $619.31^{* *}$ & $58.93^{* *}$ & $56.43^{* *}$ \\
\hline POD activity in roots & $33.48^{* *}$ & $25.07^{* *}$ & $5.85^{*}$ & $13.20^{* *}$ & $9.21^{*}$ & $0.97 n s$ \\
\hline MDA content in leaves & $32.50^{* *}$ & 0.00ns & $0.46 n s$ & $56.00^{* *}$ & $0.06 n s$ & $0.23 n s$ \\
\hline MDA content in roots & $300.57^{* *}$ & $70.40^{* *}$ & $12.43^{* *}$ & $0.07 \mathrm{~ns}$ & $9.51^{*}$ & $8.71^{* *}$ \\
\hline GS activity in leaves & $5.33^{*}$ & $0.25 n s$ & $1.38 \mathrm{~ns}$ & $4.31 \mathrm{~ns}$ & $0.91 \mathrm{~ns}$ & $1.32 \mathrm{~ns}$ \\
\hline NR activity in leaves & $4.31 \mathrm{~ns}$ & $0.91 \mathrm{~ns}$ & $1.32 \mathrm{~ns}$ & $4.62 \mathrm{~ns}$ & $12.28 * *$ & $2.56 n s$ \\
\hline
\end{tabular}

ns, non-significant at $P<0.05$ level; ${ }^{*} P<0.05$; ${ }^{* *} P<0.01$ levels. 


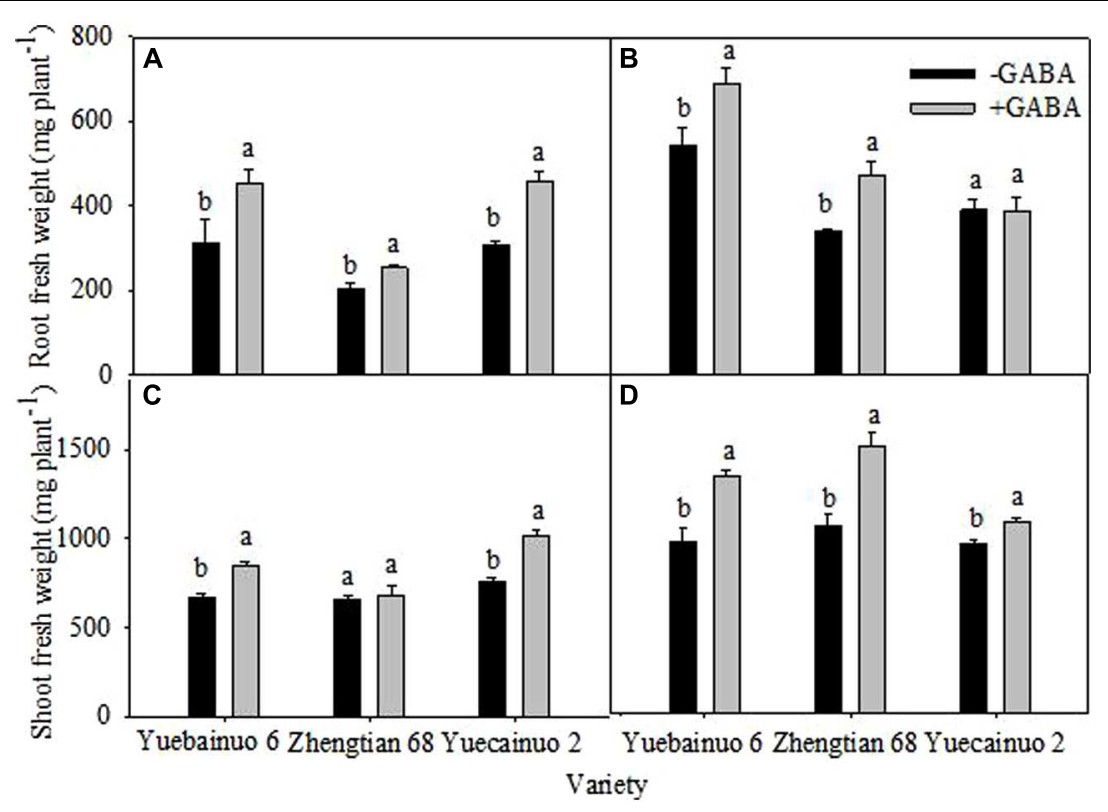

FIGURE 1 | Fresh weight of root and shoot of maize seedling at 3 DAT (A,C) and 7 DAT (B,D). Vertical bars with different lower case letters above are significantly different at $P<0.05$ by LSD tests. Capped bars represent SD $(n=4)$.

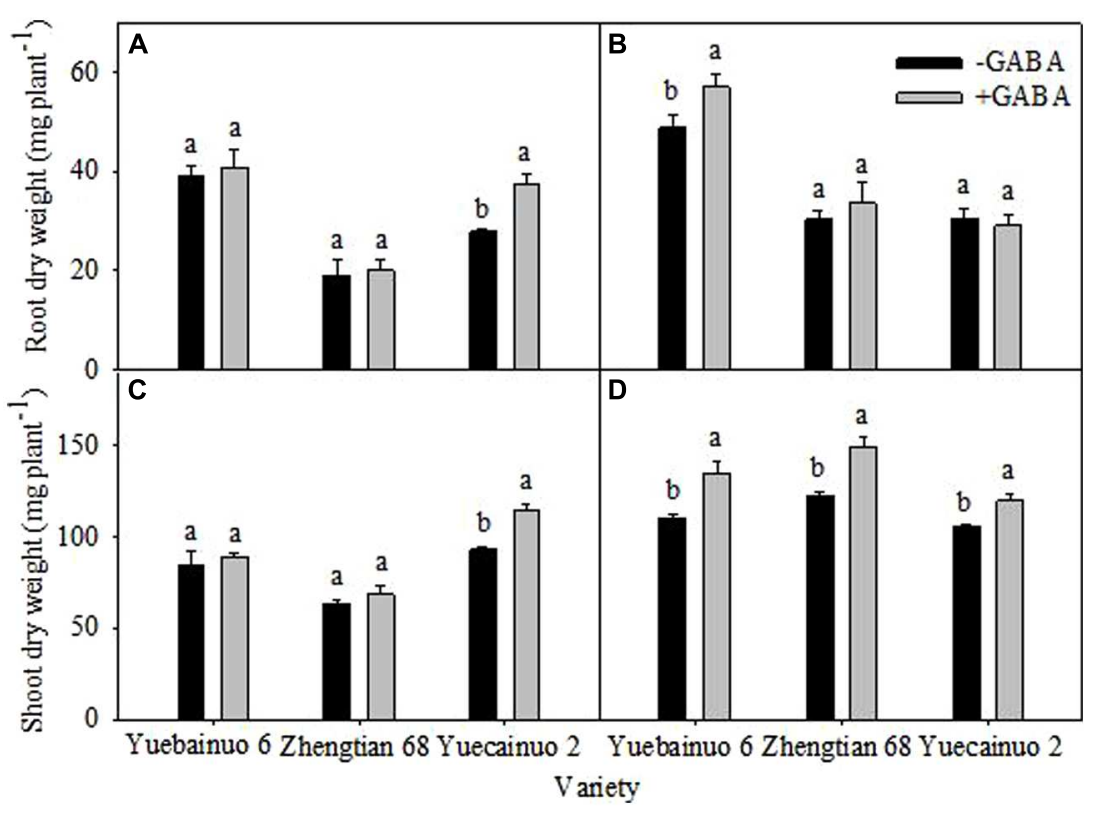

FIGURE 2 | Dry weight of root and shoot of maize seedling at 3 DAT (A,C) and 7 DAT (B,D). Vertical bars with different lower case letters above are significantly different at $P<0.05$ by LSD tests. Capped bars represent SD $(n=4)$.

Zhengtian 68 with an increment of 25.13 and $12.94 \%$ at 3 DAT, respectively; however for Yuebainuo 6, Zhengtian 68, and Yuecainuo 2, the net photosynthesis rate were $12.45,11.23$, and $13.19 \%$ higher at 7 DAT, respectively. For stomatal conductance (Gs), significant increase was found for Yuebainuo 6 upto 9.75 and $15.91 \%$ at 3 and 7 DAT, respectively (Figures 4C,D), however, there was no significant effect of
GABA on intercellular $\mathrm{CO}_{2}$ concentration (Ci) for all maize verities, except for a significant reduction of for Yuebainuo 6 at 3 DAT (Figures 4E,F). Interestingly, the transpiration rate (Tr) and stomatal conductance (Gs) showed similar trends for all three maize verities with an increase of 8.93 and $32.72 \%$ for Yuecainuo 6 at 3 and 7 DAT, respectively (Figures 4G,H). 


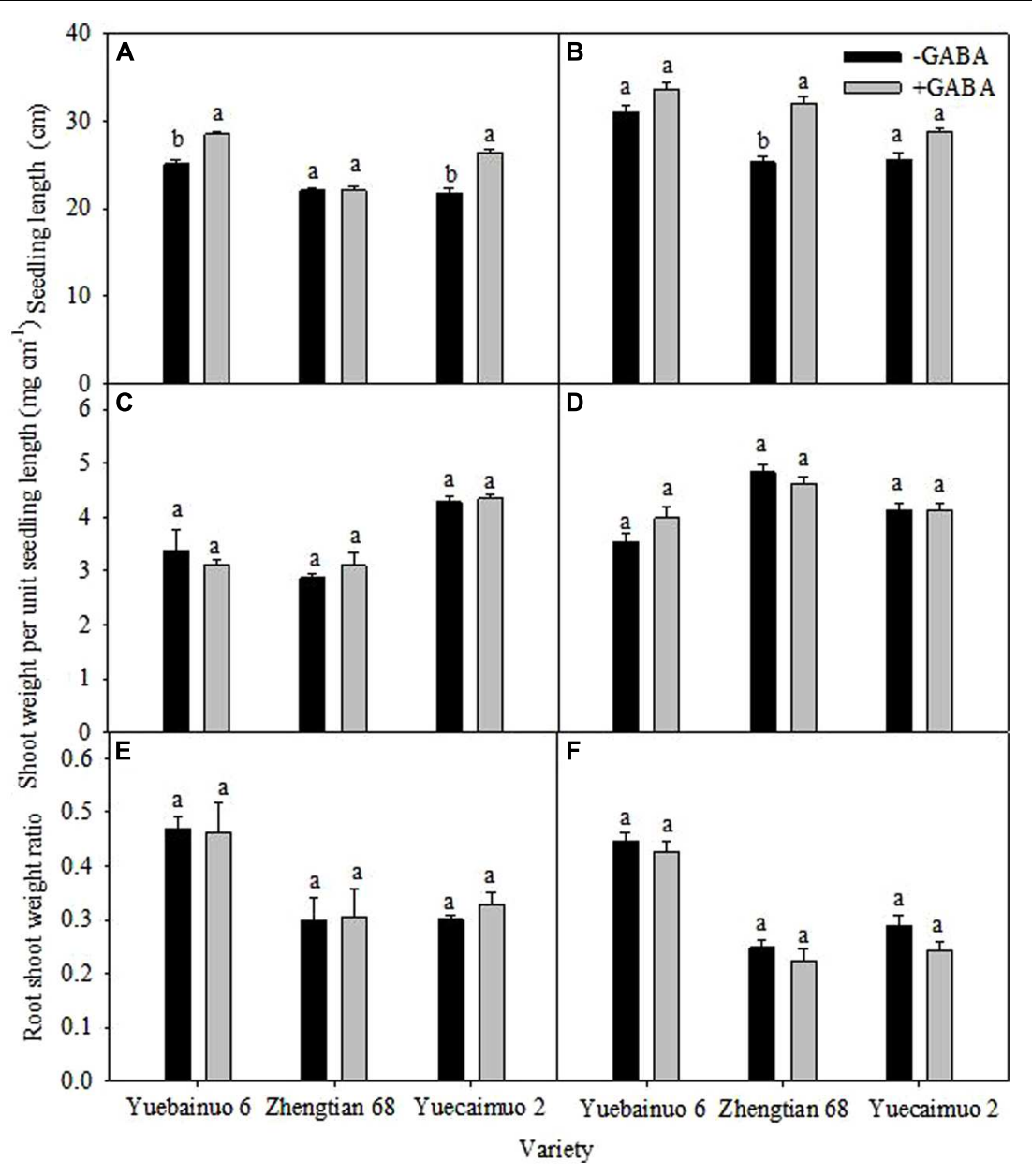

FIGURE 3 | Plant height, shoot weight per unit height, root shoot weight ratio of maize seedling at 3 DAT (A,C,E) and 7 DAT (B,D,F). Vertical bars with different lower case letters above are significantly different at $P<0.05$ by LSD tests. Capped bars represent SD $(n=4)$.

\section{SPAD Value and Protein Content}

There was no significant effect of GABA on SPAD value in leaves was observed, besides the significant reduction of SPAD for Yuebainuo 6 at 7 DAT (Figures 5A,B). For protein content in leaves, GABA application significantly improved protein content of Zhengtian 68 and Yuecainuo 2 by 11.98 and 5.77\%, respectively, at 3 DAT as well as significantly improved protein content of Yuebainuo 6 and Zhengtian 68 by 5.07 and 23.07\%, respectively, at 7 DAT (Figures $\mathbf{5 C , D}$ ). However, for protein content in root, significant reduction was recorded for all the varieties and both sampling stages (Figures 5E,F).

\section{Anti-Oxidant Enzymatic Activities}

$\gamma$-aminobutyric acid treated maize seedling increased SOD activity in root and leaves of Yuecainuo 2 significantly, the increment in leaves was 68.91 and $307.53 \%$ at 3 and 7 DAT, respectively, and in roots was 484.21 and $262.16 \%$ at 3 and 7 DAT, respectively, (Figures 6A-D). Significant increment of POD activity in leaves was recorded for Zhengtian 68 (12.68\%) at 3 DAT and for Yuecainuo 2 (95.30\%) at 7 DAT (Figures 6E,F).
For POD activity in root, the result showed 39.19 , and $14.30 \%$, higher POD activities in the roots of Yuebainuo 6 and Yuecainuo 2 , respectively, at 3 DAT whereas for Zhengtian and Yuecainuo 2 root POD activities was 3.23 and $12.40 \%$ higher at 7 DAT than non-treated maize seedlings (Figures $6 \mathrm{G}, \mathbf{H}$ ).

\section{Proline Content and MDA Content}

Exogenous GABA application did not improved proline content in leaves of all maize verities significantly at both 3 and 7 DAT (Figures 7A,B). Moreover, at 3 DAT, GABA application reduced MDA contents in roots of Yuebainuo 6 and Zhengtian 68 significantly whereas in Yuecainuo 2 MDA contents were statistically similar with non-treated seedlings while all treated maize seedlings were remained statistically similar regarding leaves MDA contents. Furthermore, at 7 DAT, leaves MDA contents of Yuebainuo 6 were considerably lower than nontreated maize seedlings while Zhengtian 68 and Yuecainuo 2 similar leaves MDA contents as non-treated seedlings (GABA). Interestingly, root MDA contents at 7 DAT were considerably higher in Yuebainuo 6 and Yuecainuo 2 under GABA treatment; nevertheless in Zhengtian 68 values for root 


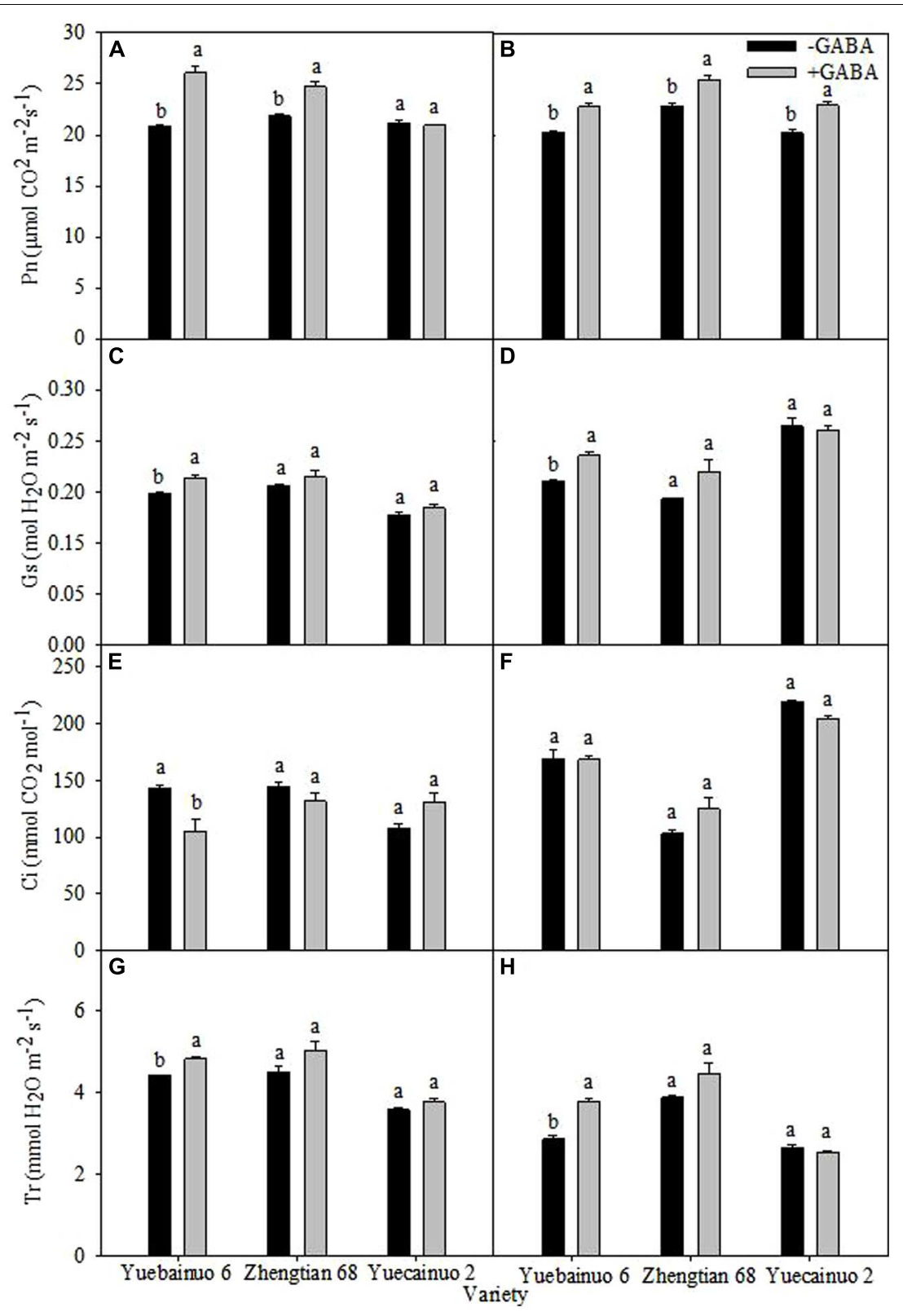

FIGURE 4 | Photosynthetic physiology of maize seedling at 3 DAT (A,C,E,G) and 7 DAT (B,D,F,H). Vertical bars with different lower case letters above are significantly different at $P<0.05$ by LSD tests. Capped bars represent $\mathrm{SD}(n=4)$.

MDA were marginally lower than non-treated maize seedlings but non-significant (Figures 7C-F).

\section{GS and NR Activity}

There was no significant difference between with and without GABA treatments regarding GS activity for the three cultivars. For NR activity, the significant differences were observed for Yuecainuo 2 at both sampling stages, the increase in NR activity could be found for the other two cultivars; however, the values were marginally higher. Overall, the increment of NR activity in leaves were remained up to $12.06,1.76$, and $19.09 \%$ higher than -GABA at 3DAT for Yuecainuo 6, Zhengtian
68 and Yuecainuo2, respectively, whilst at 7 DAT, up to $16.13,4.43$, and $11.32 \%$ higher NR activities were observed in Yuecainuo 6, Zhengtian 68, and Yuecainuo 2, respectively (Figure 8)

\section{Correlation Analyses}

Correlation analysis revealed that shoot dry weight at 7 DAT was in significantly and positively correlated with Pn and Tr in leaves at both 3 and 7 DAT. Positive associations were also recorded for the shoot dry weight at 7 DAT with NR activity in leaves, however, significance was recorded only for 7 DAT. Further, shoot dry weight at 7 DAT was negatively associated with SPAD values in 


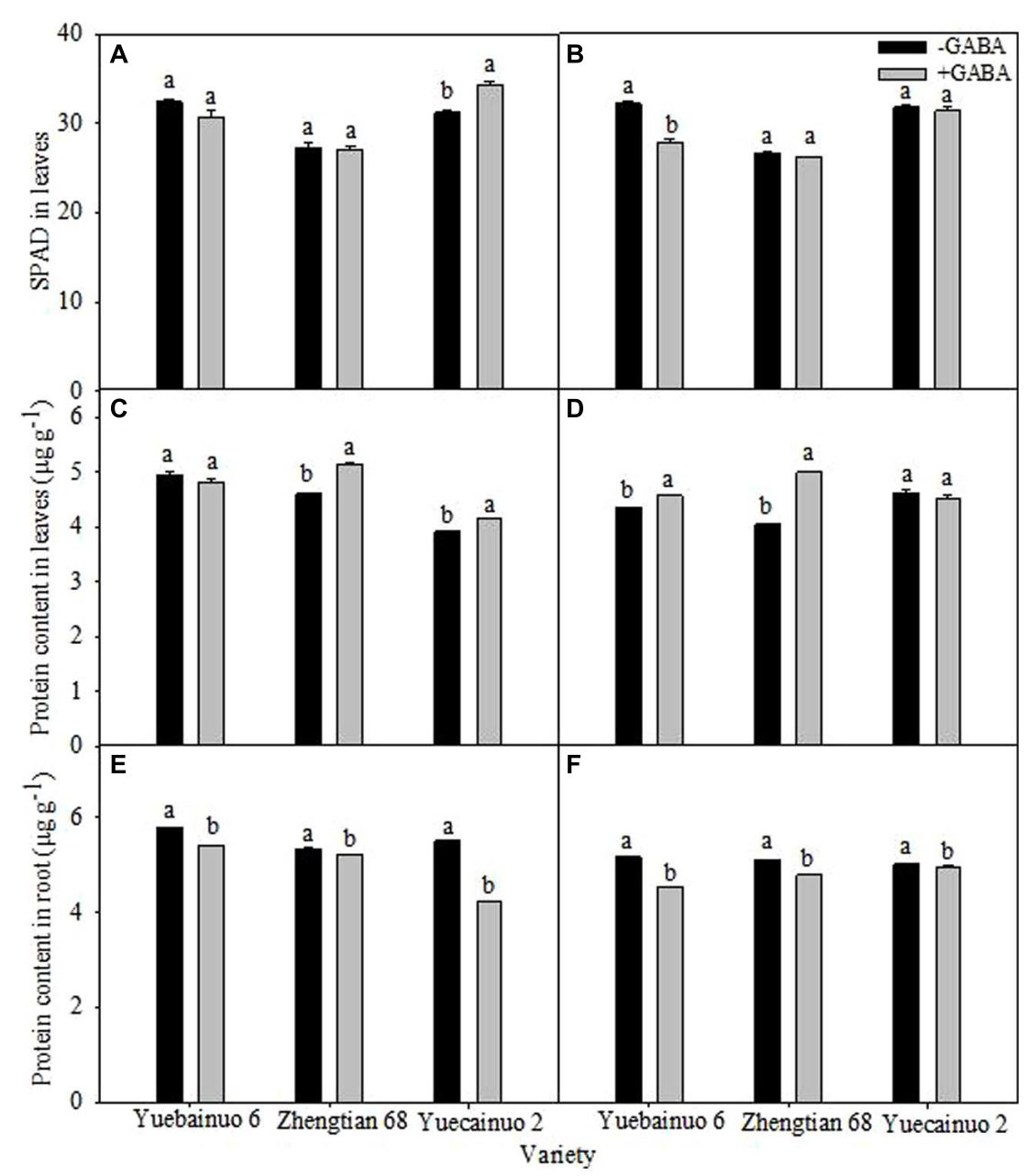

FIGURE 5 | SPAD value in leaves and protein content in leaves and root of maize seedling at 3 DAT (A,C,E) and 7 DAT (B,D,F). Vertical bars with different lower case letters above are significantly different at $P<0.05$ by LSD tests. Capped bars represent SD $(n=4)$.

leaves at both 3 and 7 DAT, but the significance was only recorded for 7 DAT (Figure 9).

\section{DISCUSSION}

$\gamma$-Aminobutyric acid (GABA), a non-protein amino acid, consists a considerable fractions of free amino acids in plant cells; however, its role in plants remained a bit unclear as compared to animal cells where its role as a neurotransmitter is wellrecognized. Regulations in cytosolic $\mathrm{pH}$, anti-oxidative enzymatic systems, buffering agent in $\mathrm{C}$ and $\mathrm{N}$ metabolism, osmoregulation, armoring against oxidative stress, and signal transduction are the major roles of GABA that might lead to improvement in overall plant performance (Kinnersley and Lin, 2000; Bouche and Fromm, 2004)

In present study, exogenous GABA application significantly improved morphological growth of seedlings of three maize cultivars, i.e., Yuecainuo 6, Zhengtian 68, and Yuecainuo 2 in terms of improved root-shoot fresh and dry biomass, seedling length, and root/shoot ratio (Figures 1-3). Previously, studies declared GABA-induced improvement in many plant species that might be due to improved photosynthetic activities, relative water contents, osmolyte accumulation, leaf turgor and other related physio-metabolical mechanisms (Deewatthanawong et al., 2010; Shang et al., 2011; Yang et al., 2011; Nayyar et al., 2014). GABA application might have promoted the maize seedlings growth by inciting cell elongation and division or/and by maintaining metabolic balance within plant tissues. Moreover, in another experiment, GABA application at 250 and $5 \mu \mathrm{M}$ enhanced growth of Stellaria longipes and Lemna, respectively, under normal growing conditions (Kathiresan et al., 1998; Kinnersley and Lin, 2000).

Plant photosynthesis and transpiration rates are affected by various factors while improvements in photosynthetic yields and high photosynthetic acclimation would be of great interest in a crop like maize (Ashraf et al., 2016). Our results revealed that exogenous GABA application promoted net photosynthesis, gas exchange capacities and chlorophyll biosynthesis in all maize cultivars under study (Figures 4 and 5). 


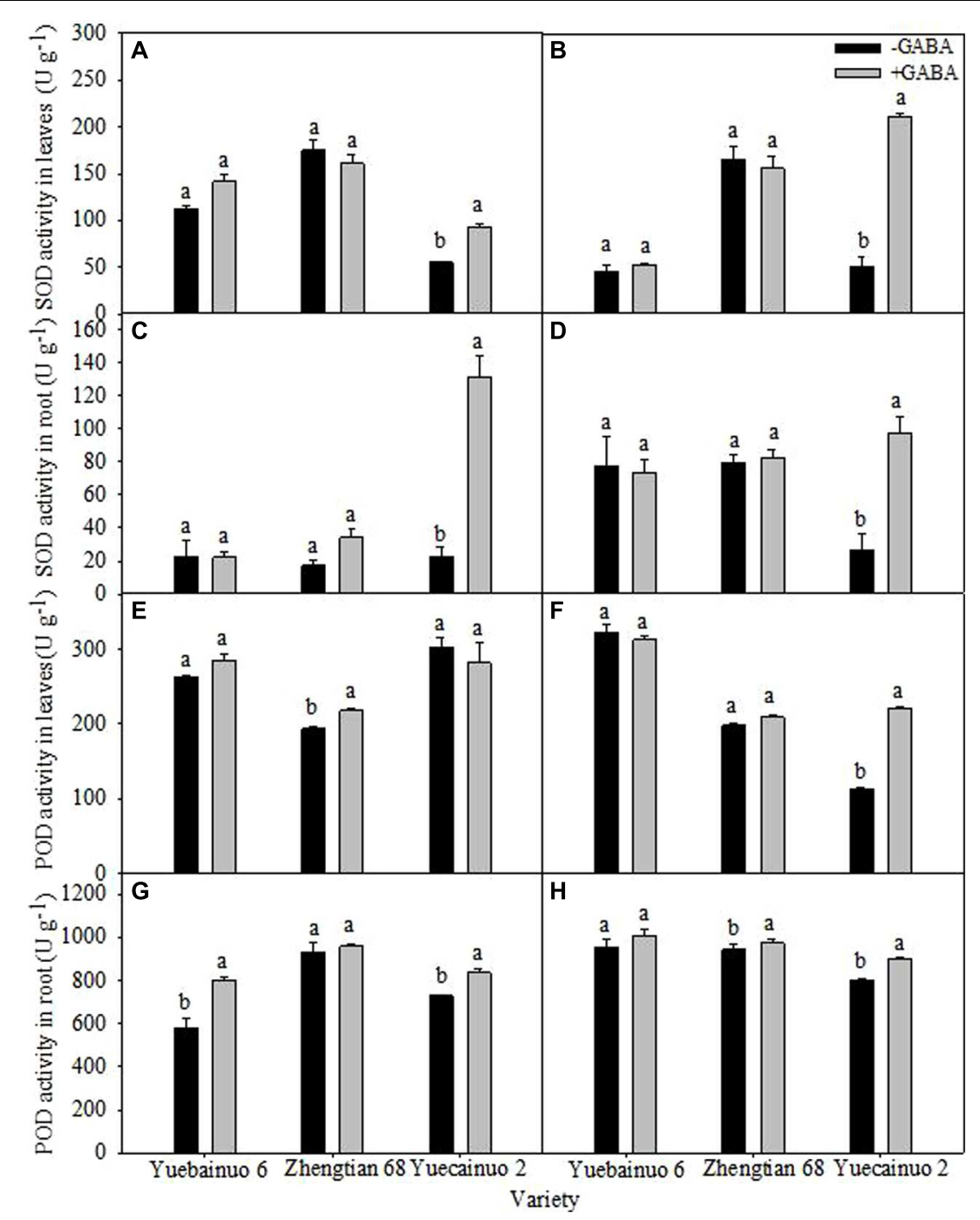

FIGURE 6 | Super-oxide dismutase and POD activity in leaves and root of maize seedling at 3 DAT (A,C,E,G) and 7 DAT (B,D,F,H). Vertical bars with different lower case letters above are significantly different at $P<0.05$ by LSD tests. Capped bars represent SD $(n=4)$.

GABA application related improvement in net photosynthesis and gas exchange in terms of stomatal conductance, intercellular $\mathrm{CO}_{2}$ concentration, transpiration rate in all maize cultivars of possibly due to maintenance of cell turgor, promoted chlorophyll biosynthesis, reduced oxidative damage by regulating various physio-biochemical processes. GABA could promote the synthesis of photosynthetic pigments and carotenoids that might be helpful in nurturing photosynthetic machinery. In a recent study, Vijayakumari and Puthur (2016) found a significant increase in the activities of photosystem I and II in Piper nigrum Linn. Plants, when seeds were primed with GABA. In contrast, effects of GABA application on net photosynthesis, chlorophyll contents and some parameters of chlorophyll fluorescence, i.e., maximal photochemical efficiency of photosystem II (Fv/Fm) and non-photochemical quenching coefficient (NPQ) were not improved significantly with GABA application whilst promotive effects were more prominent on electron transport rate (ETR), actual photochemical efficiency ( $\Phi$ PSII) and photochemical quenching coefficient $(\mathrm{qP})$ and $\mathrm{Chl} \mathrm{a} / \mathrm{b}$ in tomato seedlings grown in hydroponic culture (Luo et al., 2011). Strong shielding effects of GABA on photosynthetic machinery and chlorophyll contents in rice seedlings under heat stress were also reported by Nayyar et al. (2014).

Cytosolic accumulation of osmolytes is important to maintain cell turgor and involved in osmoregulation (Anjum et al., 2016). Our results indicated that GABA application enhanced protein contents in leaves of all maize cultivars while lowered in roots (Figure 5) whilst accumulation of proline concentration remained non-significant (Figure 7). Sustained photosynthesis, protection against protein and enzymes degradation as well as osmoregulation is the most apparent physiological effects of proline (Hare et al., 1999). Previously, GABA at 1, $510 \mathrm{mM}$ was applied to peach fruit (Prunus persica) and its application at $5 \mathrm{mM}$ led to significant increase in proline accumulation (Shang 


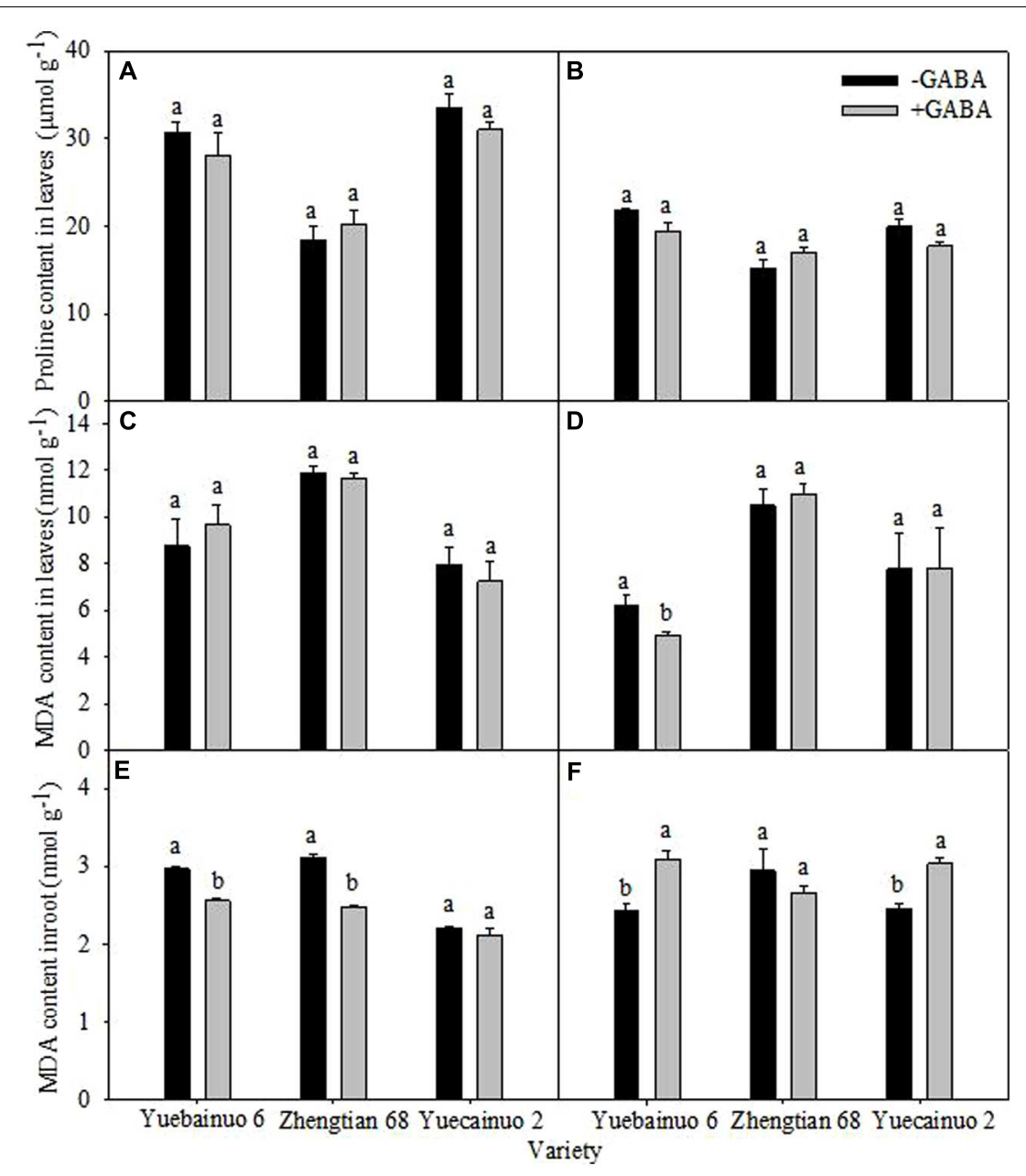

FIGURE 7 | Proline content in leaves and MDA in root and leaves of maize seedling at 3 DAT (A,C,E) and 7 DAT (B,D,F).Vertical bars with different lower case letters above are significantly different at $P<0.05$ by LSD tests. Capped bars represent SD $(n=4)$.

et al., 2011). Proline inducted protection of thylakoid membrane from oxidative damage caused by ROS is also of great importance (Delauney and Verma, 1993).

$\gamma$-aminobutyric acid induced regulations in enzymatic activities (GS and NR activity in leaves), lipid peroxidation (in terms of malnodialdehyde accumulation) and anti-oxidants (SOD and POD) in roots and leaves were represented in (Figures 6-8). Activities of GS and NR as well as anti-oxidants (SOD and POD) were found higher in seedlings supplemented with GABA (Figure 6), however, GABA application lowered MDA contents at 3 and 7 DAT except Yuebainuo 6 and Yuecainuo 2 at 7 DAT where values for MDA were significantly higher under GABA treated maize seedlings (Figure 7). GABA maintains $\mathrm{C}: \mathrm{N}$ balance, nitrogen metabolism by regulating nitrogen continuing compounds (Kinnersley and Turano, 2000; Bouche and Fromm, 2004). During nitrogen destitution, its positive correlation was with nitrate influx during whole growth period of rape which evidences its involvement in nitrogen metabolism (Bown and Shelp, 1989; Beuve et al., 2004). GABA-induced regulations in nitrogen and carbon metabolism involved enzymes including NR, GS were also noted in Arabidopsis thaliana seedlings (Barbosa et al., 2010 whereas GABA-related modulation of GS activity in Lemna minorwere also observed by Rhodes et al. (1975). Moreover, our results also demonstrated that GABA might have an effect on NR activity and phosphorylation (as activity of GR was increased due to GABA application), and might play important roles in $N$-metabolism.

On the other hand, generation of ROS often caused membrane damage and disintegration of various cellular structures and organelles thus cause ultimate cell death (Mittler et al., 2004; Ashraf et al., 2015; Anjum et al., 2016), however, timely action of SOD and POD against ROS in GABA treated maize seedlings to protect membrane damage indicated potential of GABA to in maintaining cell integrity. GABA-induced maintenance of higher activities of anti-oxidants is crucial to improve plants' ability against oxidative stress. Our results corroborated with the outcomes of Shi et al. (2010) who resulted that GABA modified the activities of various anti-oxidants to scavenge ROS in Caragana intermedia plants. Furthermore, GABA-mediated shielding effect on membrane integrity by 


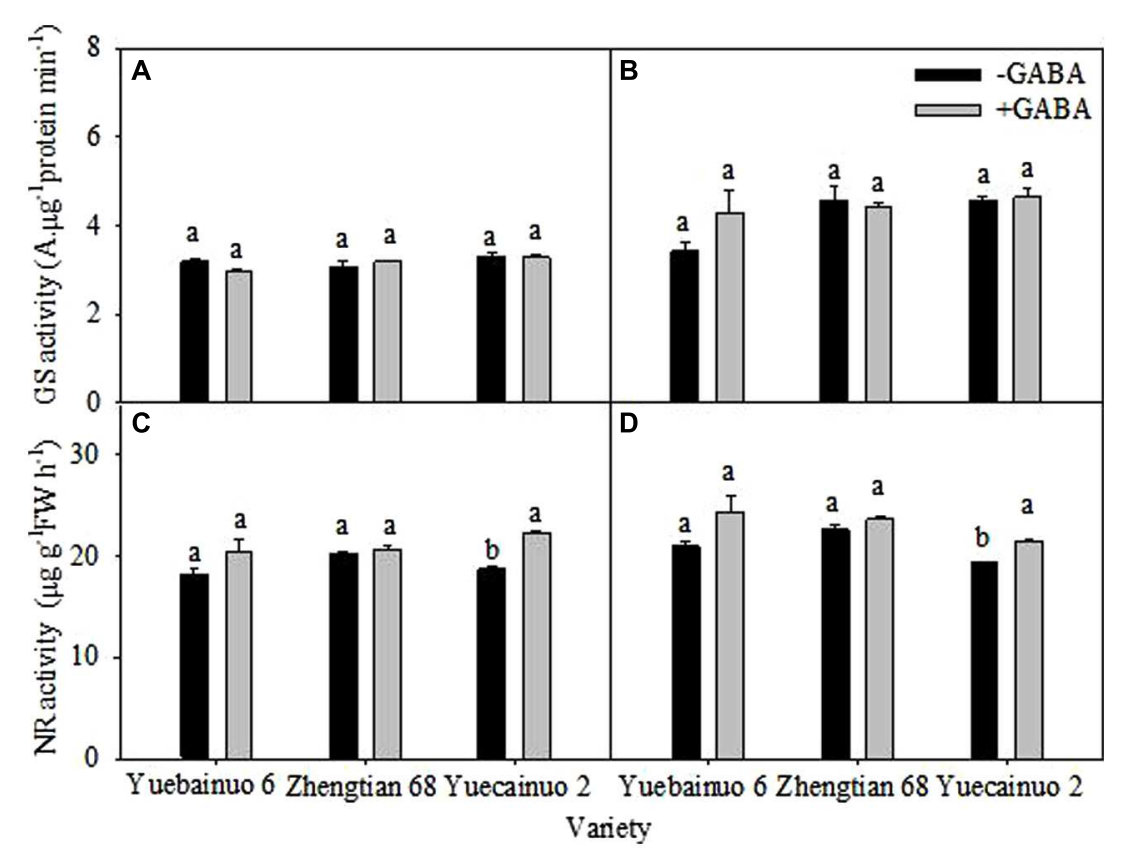

FIGURE 8 | Glutamine synthetase and NR activity in leaves of maize seedling at 3 DAT (A,C) and 7 DAT (B,D). Vertical bars with different lower case letters above are significantly different at $P<0.05$ by LSD tests. Capped bars represent $\mathrm{SD}(n=4)$.
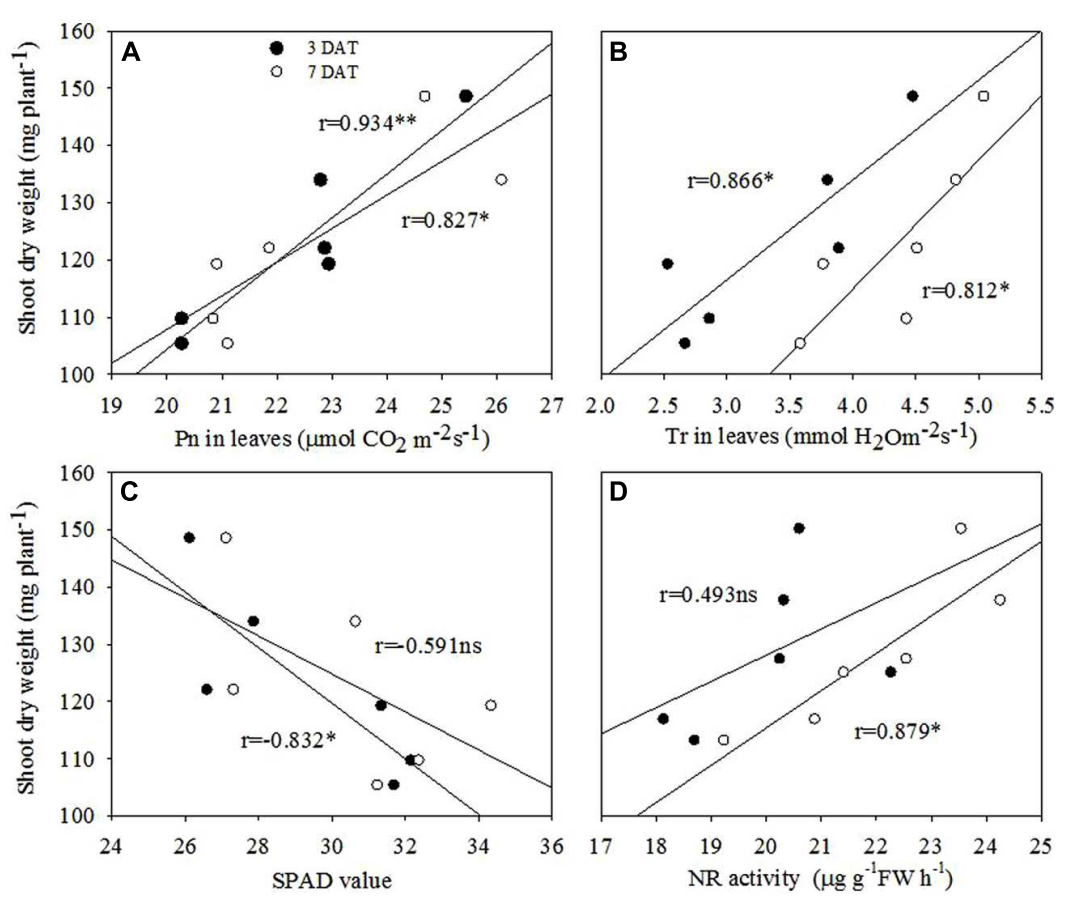

FIGURE 9 | Correlation analyses between (A) shoot dry weight and Pn in leaves, (B) shoot dry weight and Tr in leaves, (C) shoot dry weight and SPAD value, and (D) shoot dry weight and NR activity in leaves of maize seedling at 3 DAT and 7 DAT. ns, non-significant at $P<0.05$ level; *, significant at $P<0.05$; **, significant at $P<0.01$ levels.

controlling lipid peroxidation was also observed by Song et al. (2010) in barley seedlings. Overall, GABA could improve the nitrogen metabolism, anti-oxidative defense and reduced lipid peroxidation in maize seedlings. However, in our experiment, we sprayed $50 \mathrm{mg} / \mathrm{L}$ GABA but no control was included with $50 \mathrm{mg} / \mathrm{L}$ of amonium or another amino acid. We can 
therefore not distinguish between specific GABA signaling effects from effects of nitrogen fertilization through the leaves or roots which suggest further research is needed in future. However, GABA could improve nitrogen metabolism and anti-oxidative defense in maize seedlings. Endogenous GABA concentrations can play a role as a signaling molecule at low concentrations $(<10 \mu \mathrm{M})$ while at higher concentrations $(>1 \mathrm{mM})$, its involvement in various physio-metabolical processes, $\mathrm{C} / \mathrm{N}$ metabolism, osmoregulation, plant defense responses, cytosolic $\mathrm{pH}$ homeostasis and protection of plants from oxidative damage has great importance (Kinnersley and Lin, 2000; Bouche and Fromm, 2004).

\section{CONCLUSION}

This study revealed that application of GABA could improve maize seedling growth; while the increment of morphological growth is associated with net photosynthetic rate and gas exchange capacities as well as the improved antioxidant enzyme activities to scavenge ROS. Nitrogen metabolism in terms of improved NR and GS activities were also noted under GABA treated maize seedlings. In future, further studies are still needed at molecular levels to get better insight of GABA involvement in physio-biochemical processes and nitrogen metabolism related to better performance of crop plants.

\section{REFERENCES}

Anjum, S. A., Ashraf, U., Khan, I., Tanveer, M., Ali, M., Hussain, I., et al. (2016). Chromium and aluminum phyto-toxicity in maize; morpho-physiological responses and metal uptake. Clean Soil Air Water doi: 10.1002/clen.201500532

Anjum, S. A., Farooq, M., Wang, L. C., Xue, L. L., Wang, S. G., Wang, L., et al. (2011a). Gas exchange and chlorophyll synthesis of maize cultivars are enhanced by exogenously-applied glycinebetaine under drought conditions. Plant Soil Environ. 57, 326-331.

Anjum, S. A., Wang, L. C., Farooq, M., Hussain, M., Xue, L. L., and Zou, C. M. (2011b). Brassinolide application improves the drought tolerance in maize through modulation of enzymatic antioxidants and leaf gas exchange. J. Agron. Crop Sci. 197, 177-185. doi: 10.1111/j.1439-037X.2010.00459.x

Anjum, S. A., Wang, L., Farooq, M., Xue, L., and Ali, S. (2011c). Fulvic acid application improves the maize performance under well-watered and drought conditions. J. Agron. Crop Sci. 197, 409-417. doi: 10.1111/j.1439037X.2011.00483.x

Ashraf, U., Kanu, A. S., Mo, Z., Hussain, S., Anjum, S. A., Khan, I., et al. (2015). Lead toxicity in rice: effects, mechanisms, and mitigation strategies-a mini review. Environ. Sci. Pollut. Res. 22, 18318-18332. doi: 10.1007/s11356-0155463-x

Ashraf, U., Salim, M. N., Sher, A., Sabir, S. R., Khan, A., Pan, S., et al. (2016). Maize growth, yield formation and water-nitrogen usage in response to varied irrigation and nitrogen supply under semi-arid climate. Turk. J. Field. Crops 21, 87-95. doi: 10.17557/tjfc.93898

Barbosa, J. M., Singh, N. K., Cherry, J. H., and Locy, R. D. (2010). Nitrate uptake and utilization is modulated by exogenous $\gamma$-aminobutyric acid in Arabidopsis thaliana seedlings. Plant Physiol. Biochem. 48, 443-450. doi: 10.1016/j.plaphy.2010.01.020

Bates, L. S., Waldren, R. P., and Teare, I. D. (1973). Rapid determination of free proline for water stress studies. Plant Soil 39, 205-207. doi: 10.1007/BF00018060

Beuve, N., Rispail, N., Laine, P., Clquent, J. B., Ourry, A., and Le Deunff, E. (2004). Putative role of $\gamma$-aminobutyric acid (GABA) as a long distance signal in upregulation of nitrate uptake in Brassica napus L. Plant Cell Environ. 27, 1035-1046. doi: 10.1111/j.1365-3040.2004.01208.x

\section{AUTHOR CONTRIBUTIONS}

WL, JL, GL, and JH designed the research. WL, JL, GL, YL, LG, and WL performed the experiments and collected the data. UA, FH, WL, JH, and WL analyzed the data and wrote the manuscript. UA, FH, LG, YL, and $\mathrm{XT}$ edited the manuscript and provided guidance during experimentation.

\section{ACKNOWLEDGMENTS}

We acknowledge the funding provided by the Special Fund for Foundation of the President of the Guangdong Academy of Agricultural Sciences (201510), Foundation of the President of the Guangdong Academy of Agricultural Sciences (201407), and Guangdong Province Science and Technology Program Project (\#2013B020301015), Science and Technology Planning Project of Guangdong Province (2014B070706012, 2014A020208061), Guangdong Academy of Agricultural Science and Technology Research Projects (2011A020102010), and The Science and Technology Planning Project of Guangdong Province (2016A030303030). Moreover, authors would also like to acknowledge the reviewers for their useful comments and suggestions in improving the quality of this manuscript.

Bouche, N., and Fromm, H. (2004). GABA in plants: just a metabolite? Trends Plant Sci. 9, 110-115. doi: 10.1016/j.tplants.2004.01.006

Bown, A. W., and Shelp, B. J. (1989). The metabolism and physiological roles of 4-aminobutyric acid. Biochem. Life Sci. Adv. 8, 21-25.

Bradford, M. M. (1976). A rapid and sensitive method for the quantitation of microgram quantities of protein utilizing the principle of protein-dye binding. Anal. Biochem. 72, 248-254. doi: 10.1016/0003-2697(76)90527-3

Carroll, A. D., Phillips, R., Ratcliffe, R. G., and Stewart, G. R. (1994). Ammonium assimilation and the role of $\gamma$-aminobutyric acid in $\mathrm{pH}$ homeostasis in carrot cell suspensions. Plant Physiol. 106, 513-520. doi: 10.1104/pp.106.2.513

Chen, J. X., and Wang, X. F. (2006). Plant Physiology Experiment Instruction. Guangzhou: South China University of Technology Press.

Deewatthanawong, R., Nock, J. F., and Watkins, C. B. (2010). $\gamma$-Aminobutyric acid (GABA) accumulation in four strawberry cultivars in response to elevated CO2 storage. Postharvest Biol. Technol. 57, 92-96. doi: 10.1016/j.postharvbio.2010.03.003

Delauney, A. J., and Verma, D. P. S. (1993). Proline biosynthesis and osmoregulation in plants. Plant J. 4, 215-223. doi: 10.1046/j.1365313X.1993.04020215.x

Hare, P. D., Cress, W. A., and Van Staden, J. (1999). Proline synthesis and degradation: a model system for elucidating stress-related signal transduction. J. Exp. Bot. 50, 413-434. doi: 10.1093/jxb/50.333.413

Kathiresan, A., Miranda, J., Chinnappa, C. C., and Reid, D. M. (1998). $\gamma-$ aminobutyric acid promotes stem elongation in Stellarialongipes: the role of ethylene. Plant Growth Regul. 26, 131-137. doi: 10.1023/A:10061078 15064

Kinnersley, A. M., and Lin, F. (2000). Receptor modifiers indicate that 4aminobutyric acid (GABA) is a potential modulator of ion transport in plants. Plant Growth Regul. 32, 65-76. doi: 10.1023/A:1006305120202

Kinnersley, A. M., and Turano, F. J. (2000). Gamma-aminobutyric acid (GABA) and plant responses to stress. Crit. Rev. Plant Sci. 19, 479-509. doi: $10.1080 / 07352680091139277$

Lancien, M., and Roberts, M. R. (2006). Regulation of Arabidopsis thaliana 14-3-3 gene expression by $\gamma$-aminobutyric acid. Plant Cell Environ. 29, 1430-1436. doi: 10.1111/j.1365-3040.2006.01526.x 
Li, M., Ashraf, U., Tian, H., Mo, Z., Pan, S., Anjum, S. A., et al. (2016). Manganeseinduced regulations in growth, yield formation, quality characters, rice aroma and enzyme involved in 2-acetyl-1-pyrroline biosynthesis in fragrant rice. Plant Physiol. Biochem. 103, 167-175. doi: 10.1016/j.plaphy.2016.03.009

Luo, H. Y., Gao, H. B., Xia, Q. P., Gong, B. B., and Xiao-Lei, W. U. (2011). Effects of exogenous GABA on reactive oxygen species metabolism and chlorophyll fluorescence parameters in tomato under $\mathrm{NaCl}$ stress. Scientia Agricultura Sinica 34, 37-544.

Ma, H. (2003). Plant reproduction: GABA gradient, guidance and growth. Curr. Biol. 13, 834-836. doi: 10.1016/j.cub.2003.10.015

Masclaux-Daubresse, C., Valadier, M.-H., Carrayol, E., Reisdorf-Cren, M., and Hirel, B. (2002). Diurnal changes in the expression of glutamate dehydrogenase and nitrate reductase are involved in the $\mathrm{C} / \mathrm{N}$ balance of tobacco source leaves. Plant Cell Environ. 25, 1451-1462. doi: 10.1046/j.1365-3040.2002. 00925.x

Mittler, R., Vanderauwera, S., Gollery, M., and Van Breusegem, F. (2004). Reactive oxygen gene network of plants. Trends Plant Sci. 9, 490-498. doi: 10.1016/j.tplants.2004.08.009

Mo, Z., Huang, J., Xiao, D., Ashraf, U., Duan, M., Pan, S., et al. (2016). Supplementation of 2-Ap, $\mathrm{Zn}$ and $\mathrm{La}$ improves 2-acetyl-1-pyrroline concentrations in detached aromatic rice panicles in vitro. PLOS ONE 11: e0149523. doi: 10.1371/journal.pone.0149523

Nayyar, H., Kaur, R., Kaur, S., and Singh, R. (2014). $\gamma$-aminobutyric acid (GABA) imparts partial protection from heat stress injury to rice seedlings by improving leaf turgor and upregulating osmoprotectants and antioxidants. J. Plant Growth Regul. 33, 408-419. doi: 10.1007/s00344-013-9389-6

Pan, S., Wen, X., Mo, Z. W., Duan, M., Dong, H.,Huang, G., et al. (2015). Effects of nitrogen application and shading on yields and some physiological characteristics in different rice genotypes. Chin. J. Rice Sci. 29, 141-149. doi: 10.3969/j.issn.1001-7216.2015.02.005

Rhodes, D., Rendon, G. A., and Stewart, G. R. (1975). The control of glutamine synthetase level in Lemna minor L. Planta 125, 201-211. doi: 10.1007/BF00385596

Rhodes, D., Verslues, P. E., and Sharp, R. E. (1999). "Role of amino acids in abiotic stress resistance," in Plant Amino Acids: Biochemistry and Biotechnology, ed. B. K. Singh, (New York, NY: Marcel Dekker), 319-356.

Roberts, M. R. (2007). Does GABA act as a signal in plants? Hints from molecular studies. Plant Signal. Behav. 2, 408-409. doi: 10.4161/psb.2. 5.4335

Shang, H., Shifeng, C., Zhenfeng, Y., Yuting, C., and Yonghua, Z. (2011). Effect of exogenous $\gamma$-aminobutyric acid treatment on proline accumulation and chilling injury in peach fruit after long-term cold storage. J. Agric. Food Chem. 59, 1264-1268. doi: 10.1021/jf104424z

Shelp, B. J., Bown, A. W., and McLean, M. D. (1999). Metabolism and functions of gamma-aminobutyric acid. Trends Plant Sci. 4, 446-452. doi: 10.1016/S13601385(99)01486-7

Shi, S. Q., Shi, Z., Jiang, Z. P., Qi, L. W., Sun, X. M., Li, C. X., et al. (2010). Effects of exogenous GABA on gene expression of Caragana intermedia roots under $\mathrm{NaCl}$ stress: regulatory roles for $\mathrm{H} 2 \mathrm{O} 2$ and ethylene production. Plant Cell Environ. 33, 149-162. doi: 10.1111/j.1365-3040.2009.02065.x

Song, H., Xu, X., Hua, W., Wang, H., and Tao, Y. (2010). Exogenous $\gamma$-aminobutyric acid alleviates oxidative damage caused by aluminium and proton stresses on barley seedlings. J. Sci. Food Agri. 90, 1410-1416. doi: 10.1002/jsfa.3951

Sun, Y. J., Sun, Y. Y., Li, X. Y., Guo, X., and Ma, J. (2009). Relationship of nitrogen utilization and activities of key enzymes involved in nitrogen metabolism in rice under water-nitrogen interaction. Acta Agron. Sin. 35, 2055-2063. doi: 10.3724/SP.J.1006.2009.02055

Vijayakumari, K., and Puthur, J. T. (2016). $\gamma$-aminobutyric acid (GABA) priming enhances the osmotic stress tolerance in piper nigrum Linn. plants subjected to peg-induced stress. Plant Growth Regul. 78, 57-67. doi: 10.1007/s10725-0150074-6

Yang, A., Cao, S., and Yang, Z. (2011). $\gamma$-aminobutyric acid treatment reduces chilling injury and activates the defence response of peach fruit. Food Chem. 129, 1619-1622. doi: 10.1016/j.foodchem.2011.06.018

Yu, G. H., and Sun, M. X. (2007). Deciphering the possible mechanism of GABA in tobacco pollen tube growth and guidance. Plant Signal. Behav. 2, 393-395. doi: 10.4161/psb.2.5.4265

Wu, F. B., Wu, L. H., and Xu, F. H. (1998). Chlorophyll meter to predict nitrogen side dress requirements for short-season cotton (Gossypium hirsutum L.). Field Crops Res. 56, 309-314. doi: 10.1016/S0378 4290(97)00108-1

Conflict of Interest Statement: The authors declare that the research was conducted in the absence of any commercial or financial relationships that could be construed as a potential conflict of interest.

Copyright $@ 2016 \mathrm{Li}$, Liu, Ashraf, Li, Li, Lu, Gao, Han and Hu. This is an open-access article distributed under the terms of the Creative Commons Attribution License (CC BY). The use, distribution or reproduction in other forums is permitted, provided the original author(s) or licensor are credited and that the original publication in this journal is cited, in accordance with accepted academic practice. No use, distribution or reproduction is permitted which does not comply with these terms. 